\title{
Sorting in experiments with application to social preferences
}

\author{
Lazear, Edward P ; Malmendier, Ulrike ; Weber, Roberto A
}

\begin{abstract}
Individuals sort into and out of economic environments based on their preferences and in response to relative prices. We demonstrate the importance of such sorting for the measurement of social preferences, using two laboratory experiments. First, allowing subjects to avoid environments in which sharing is possible significantly reduces sharing. This reveals the existence of a type of individual who shares reluctantly, preferring to avoid the opportunity to share. Second, after subsidizing the sharing environment, the aggregate amount shared increases, but less is shared, on average, by those who enter. Thus, subsidies intended to induce more sharing have weak effects since they attract those who share the least.
\end{abstract}

DOI: https://doi.org/10.1257/app.4.1.136

Posted at the Zurich Open Repository and Archive, University of Zurich

ZORA URL: https://doi.org/10.5167/uzh-61221

Journal Article

Published Version

Originally published at:

Lazear, Edward P; Malmendier, Ulrike; Weber, Roberto A (2012). Sorting in experiments with application to social preferences. American Economic Journal: Applied Economics, 4(1):136-163.

DOI: https://doi.org/10.1257/app.4.1.136 


\title{
Sorting in Experiments with Application to Social Preferences ${ }^{\dagger}$
}

\author{
By Edward P. Lazear, Ulrike Malmendier, and Roberto A. Weber*
}

\begin{abstract}
Individuals sort into and out of economic environments based on their preferences and in response to relative prices. We demonstrate the importance of such sorting for the measurement of social preferences, using two laboratory experiments. First, allowing subjects to avoid environments in which sharing is possible significantly reduces sharing. This reveals the existence of a type of individual who shares reluctantly, preferring to avoid the opportunity to share. Second, after subsidizing the sharing environment, the aggregate amount shared increases, but less is shared, on average, by those who enter. Thus, subsidies intended to induce more sharing have weak effects since they attract those who share the least. (JEL C91, D12, D64)
\end{abstract}

\begin{abstract}
ocial preferences have been shown to strongly affect individual behavior both in the laboratory, e.g., in dictator games, and in the field, e.g., for charitable giving. ${ }^{1}$ A large prior literature provides evidence of specific types of social preferences, such as pure or impure altruism and reciprocity, and links these preferences to sharing behavior (Fehr and Schmidt 2002). However, the existence, or even prevalence, of certain types of social preferences does not immediately imply that they are an important determinant of real-world sharing behavior. In order for sharing to occur frequently in economic contexts, individuals with pro-social types must be willing to place themselves in situations in which they have the opportunity to share.

In this paper, we argue that such sorting, whereby some individuals opt into environments in which sharing is possible while others avoid these environments, has a strong effect on how much pro-social behavior is observed. Moreover, if individuals
\end{abstract}

\footnotetext{
* Lazear: Stanford University, Graduate School of Business, Knight Management Center, 655 Knight Way, E346, Stanford, CA 94305-7298 (e-mail: lazear@stanford.edu); Malmendier: University of California, Berkeley, Department of Economics, 508-1 Evans Hall \#3880, Berkeley, CA 94720-3880 (e-mail: ulrike@econ.berkeley. edu); Weber: University of Zurich, Department of Economics, Blümlisalpstrasse 10, CH-8006 Zürich (e-mail: roberto.weber@econ.uzh.ch). Previous versions of this paper were circulated under the titles "Sorting, Prices, and Social Preferences," "Sorting in Experiments," and "Sorting and Social Preferences." A longer version with more experiments is available on our websites under the title "Sorting, Prices, and Social Preferences." We thank Jordi Brandts, Colin Camerer, Stefano DellaVigna, Hank Farber, Ernst Fehr, Glenn Harrison, Larry Katz, Pat Kline, Botond Köszegi, Matthew Rabin, Klaus Schmidt, Georg Weizsäcker, as well as participants at several seminars and conferences for helpful comments. We also thank several anonymous referees for helpful comments and suggestions. We also thank Yiwen Cheng, Jason Dana, Pauline Leung, David Liu, Aniol Llorente, Scott Rick, David Rodriguez, and Jeslyn Su for help in conducting the experiments and the Pittsburgh Experimental Economics Laboratory (PEEL), the Laboratori d'Economia Experimental (LEEX) in Barcelona, and the Berkeley Experimental Social Science Laboratory (XLab) for access to their resources.

$\dagger$ To comment on this article in the online discussion forum, or to view additional materials, visit the article page at http://dx.doi.org/10.1257/app.4.1.136.

${ }^{1}$ For reviews of the vast literature see, e.g., Camerer (2003) and Andreoni (2006).
} 
have the opportunity to opt into or out of real-world sharing environments, a laboratory experiment intended to assess the influence of social preferences should allow for that option. If not, the results of the experiment are less likely to be applicable to the real world. For example, some of the most popular fundraising methods (doorto-door, donor lists, phone solicitation) involve being directly approached by the fundraiser, which makes it difficult to avoid the giving request. In response, the majority of American households use opt-out techniques such as do-not-call lists, leaving the fundraisers with a smaller and self-selected (possibly more generous) set of individuals to approach. ${ }^{2}$ Such sorting options are known to have strong effects on how much sharing ultimately takes place.

We use two laboratory experiments to show that sorting strongly affects which social-preference types are present in a given economic environment and, as a result, the observed sharing behavior. We use laboratory experiments because of the control they afford us in studying the effects of sorting on sharing, ceteris paribus, and because the majority of prior research on social preferences utilizes laboratory experiments, in particular dictator games. Our work compliments research exploring similar effects in the field, such as Della Vigna, List, and Malmendier (forthcoming) whose door-todoor fundraising experiment "with sorting options" mirrors our laboratory design. ${ }^{3}$

Our design introduces a simple form of sorting into the dictator game: participants are allowed to "opt out" of playing the dictator game and, instead, to "enter" an experimental environment where they receive a fixed payment, while the potential recipient remains uninformed about the game. Our laboratory context therefore mimics situations in which a potential giver chooses whether to enter an environment in which sharing is possible, and the potential recipient becomes aware of the possible interaction only if entry occurs. We use this abstract experimental form of "sorting in dictator games" to model the more complex kind of sorting that motivates our research: Individuals self-select into and out of environments in which they have the possibility of sharing their wealth with others. We also manipulate the price of entering the sharing environment by varying the endowment in the dictator game $(w)$ relative to the outside option $\left(w^{\prime}\right)$.

In order to better understand the effects of sorting and entry prices on sharing, we distinguish three types of social preferences based on the observed sharing behavior. First, "willing sharers" share a positive amount, if asked to, and seek the opportunity to do so. Second, "reluctant sharers" share, if asked to, but prefer to avoid the sharing environment. Third, "nonsharers" simply never share. These three classes comprise a variety of social preferences discussed in the literature. For example, "willing sharers" might be motivated by pure or impure (warm-glow) altruism (Fehr and Gächter 2000; Andreoni 1989 and 1990), or by self-signaling (Bodner and Prelec 2002; Benabou and Tirole 2006; Grossman 2009). "Reluctant sharers" may share because they feel shame, guilt, or social pressure to conform to a request (Milgram 1963; Kandel and Lazear 1992; Bernheim 1994; Tadelis 2008; Battigalli and Dufwenberg 2007; Charness and

\footnotetext{
${ }^{2}$ According to the 2009 Economic Report of the President (Box 9-1), 72 percent of Americans were registered with National Do Not Call program as of 2007.

${ }^{3}$ Similarly, Lacetera, Macis, and Slonim (2009) study the sorting implications of financial incentives for blood donations.
} 
Dufwenberg 2006; Dillenberger and Sadowski forthcoming). "Nonsharers" might have "classical" self-interested preferences, or they may feel social pressure to give but are able to resist the pressure. Our coarse distinction, based on observed behavior, suffices to generate predictions about differential sorting as the price for entry varies, and about the resulting sample composition.

In the first experiment, we introduce sorting into a dictator game. We give participants a choice between an environment that allows sharing (a dictator game with endowment $w$ ) and one that does not (potential dictators are paid a fixed amount $w^{\prime}$, and potential recipients are left unaware of the sharing possibility). We find that a costless sorting opportunity $\left(w=w^{\prime}\right)$ reduces the number of sharers by half. This implies that giving is utility-decreasing, relative to opting out of the sharing environment, for at least half of the individuals that would give a positive amount in standard dictator games. Surprisingly, also some of the most generous sharers sort out of the dictator game, suggesting that observed generosity is not a good measure of the experienced utility from giving. The sorting effect is robust across geographic locations and within demographic subsamples. In fact, sorting has considerably greater economical and statistical power to predict giving than any demographic characteristic, including social background and past charitable giving.

In the second experiment, we introduce price effects. We test whether relative prices in settings with and without sharing affect the differential sorting of individuals with different social preferences. Specifically, we make the dictator game financially more attractive relative to the outside option $\left(w>w^{\prime}\right)$. As a result, all "willing sharers" and "nonsharers" should enter; but, among the "reluctant sharers," only those should enter for whom the additional endowment $w-w^{\prime}$ more than offsets the disutility from being pressured (or shamed) into giving. We find that the subsidy leads to greater entry into the sharing environment and a higher aggregate amount shared. However, it disproportionately attracts those who share the least-nonsharers and the least generous reluctant sharers. As a result, the introduction of a small subsidy increases the total amount shared but lowers the average amount shared among entrants. Thus, subsidies intended to induce individuals to share may have weak effects since they attract those who share the least. ${ }^{4}$

The latter experiment also utilizes a within-subject design, in which we confront subjects with increasingly higher subsidies. This accomplishes two goals. First, we can show directly that those reluctant sharers who share the most in a standard dictator game (without sorting) are least willing to re-enter the dictator game. Second, the within-subjects data allows us to classify social-preference types more precisely than the between-subjects data from the first experiment, since we need to observe individuals both in an environment with and in an environment without sorting opportunity to distinguish willing and reluctant sharers.

Our results show that the opportunity to avoid a sharing environment significantly affects the measured role of social preferences. A key insight is that, in generalizing

\footnotetext{
${ }^{4}$ In unreported results, we also find that the reverse holds. When increasing the cost of entry into the sharing environment relative to the outside option $\left(w<w^{\prime}\right)$, few subjects enter, but those subjects share substantially. Hence, sharing environments with a cost of entry attract primarily those who share the most. See Lazear, Malmendier, and Weber (2010).
} 
from experiments on social preferences to the world outside the laboratory, one needs to account for the effects of individuals sorting between environments that allow different kinds of social acts. In the field, individuals sort into and out of environments based on preferences and prices. Thus, individuals who participate in a market are unlikely to be a random sample of the population. ${ }^{5}$ A significant contribution of our research is to demonstrate how the introduction of a simple kind of sorting behavior into a widely used laboratory paradigm can dramatically alter the observed results and conclusions, while also providing valuable information on how sorting is likely to impact behavior and outcomes in the field. ${ }^{6}$

In addition, allowing for sorting in experiments helps identify social preferences. In an environment where opting out is difficult, an individual may appear to be a "willing sharer" even though she actually prefers to avoid sharing. While our work does not attempt to pin down the exact preferences underlying "reluctant sharing," it reveals that looking at behavior across environments with and without sorting helps to distinguish among different motives. ${ }^{7}$

\section{Predictions: Sorting and Sharing under Heterogeneous Social Preferences}

Consider an agent who sorts into one of two possible economic settings, one with a sharing opportunity and one without. In the sharing environment, the agent is endowed with an amount $w$ and can divide $w$ into a payoff for herself $(x)$ and a payoff for another agent $(y)$. In the environment without a sharing opportunity, the agent receives a possibly different amount $w^{\prime}$, and the other agent receives nothing $(y=0)$. We allow the agent's utility to depend on the payoffs $x$ and $y$ as well as on the environment $D, U=U(D, x, y)$, where $D$ equals 1 if the environment allows sharing and 0 otherwise. ${ }^{8}$ In this framework, a sorting option means that the agent can choose between the environment with and without a sharing opportunity. Note that an agent who chooses to be in an environment obtains the same utility as an

\footnotetext{
${ }^{5}$ Critics have questioned whether experimental results based on samples selected among college students apply to "real people" performing "real tasks" (cf. Harrison and List 2004). Many such criticisms have been successfully addressed, for example, by replicating experiments with higher stakes (Hoffman, McCabe, and Smith 1996; Cameron 1999; Camerer and Hogarth 1999; Fehr, Fischbacher, and Tougareva 2002) or with professionals (see the overview in Harrison and List 2004, Section 4). The point of our paper is different. Rather than arguing that the samples are too narrow to reflect the overall population, we ask whether their selection is too broad to make inferences about the field. In addition, we demonstrate the potential of experiments to analyze sorting directly.

${ }^{6}$ Other studies have addressed the role of sorting in contexts such as prisoner's dilemma and public goods games (Bohnet and Kübler 2005; Ahn, Isaac, and Salmon 2008), the choice of reward and punishment institutions (Gürerk, Irlenbusch, and Rockenbach 2006; Haigner, Kocher, and Sutter 2006; Botelho et al. 2005), incentive contracts (Eriksson and Villeval 2004; Dohmen and Falk 2006), auctions (Palfrey and Pevnitskaya 2008), risky choices (Harrison, Lau, and Rutström 2009), partner selection in trust and dictator games (Slonim and Garbarino 2008), and entry into competitive environments (Camerer and Lovallo 1999; Niederle and Vesterlund 2007; Bartling et al. 2009).

${ }^{7}$ Similarly to us, Dana, Cain, and Dawes (2006) (see also Broberg, Ellingsen, and Johannesson 2007) analyze sharing motives and willingness to pay to avoid the dictator game, but they do not focus on the effect of sorting or price variation. Other research, e.g., Dana, Weber, and Kuang (2007) and Benabou and Tirole (2006), explores the motivation behind reluctant sharing.

${ }^{8}$ By including only "own payoff" and "others' payoff" into the utility function, we implicitly assume narrow framing. That is, the agent does not consider payoffs or wealth beyond payoffs from the current decision.
} 
agent exogenously assigned to such an environment, holding payoffs constant. ${ }^{9} \mathrm{We}$ define the proportion shared in the sharing environment to be $a=y /(x+y)$.

We distinguish three types of social preferences, based on the observed sharing behavior and on the observed sorting between the environments with and without a sharing opportunity. First, some individuals share a positive amount if in the sharing environment, $\arg \max _{x \in[0, w]} U(1, x, w-x)<w$, and they prefer to be in such an environment when $w=w^{\prime}$, i.e., $\max _{x \in[0, w]} U(1, x, w-x)>U(0, w, 0)$. This type, which we term "willing sharer," derives utility from sharing and sorts into (and shares in) a dictator game whenever the cost of entering the game is less than or equal to zero. These social preferences include a range of sharing motives, such as pure and impure altruism and inequity aversion (Andreoni 1990; Fehr and Schmidt 1999).

The second type shares a positive amount, $\arg \max _{x \in[0, w]} U(1, x, w-x)<w$, but prefers not to have the option to share when there is no monetary reward, $\max _{x \in[0, w]} U(1, x, w-x)<U(0, w, 0)$. We refer to this type as "reluctant sharer." This type share, for example, due to social pressure to comply with a sharing norm, out of shame or guilt at not sharing, due to (narrow) inequity aversion that is not felt when opting out, or due to "emotional altruism," i.e., not wanting to hurt the other person's feelings by saying no to a sharing request. We do not distinguish between these interpretations. Our goal is simply to detect reluctance to share, using the sorting option, and to assess its magnitude and responsiveness to prices. For reluctant sharers, we also investigate whether they not only prefer to opt out whenever the cost is zero $\left(w=w^{\prime}\right)$, but may even be willing to incur a positive cost $\left(w>w^{\prime}\right)$ to avoid sharing.

The third type does not share, even if the environment allows for sharing: $\arg \max _{x \in[0, w]} U(1, x, w-x)=w$. We call this type "nonsharer." Most straightforward, we can interpret nonsharers as standard economic agents who derive utility from their own payoff and are not affected by the presence of a sharing opportunity, $\max _{x \in[0, w]} U(1, x, w-x)=U(1, w, 0)=U(0, w, 0)$. In that case, nonsharers are indifferent between environments with and without sharing, and we have no prediction about their sorting when $w=w^{\prime} .{ }^{10}$ When the sharing environment yields a greater payoff $\left(w>w^{\prime}\right)$, however, we predict that they enter (and share zero).

Based on the above three kinds of social preferences, we can generate simple predictions about sharing and sorting behavior and its interaction with prices. The core proposition deals with the impact of reluctant sharers if sorting is possible at no cost.

PROPOSITION 1: The introduction of a sorting option in a sharing environment, with equal endowment in the environments with and without sharing $\left(w=w^{\prime}\right)$, reduces the aggregate amount shared.

\footnotetext{
${ }^{9}$ Alternatively, agents may obtain lower utility when choosing to avoid the sharing opportunity than when being exogenously assigned to the nonsharing environment, e.g., disutility from (self-)signaling that they prefer not to face the request to share. If such effects exist, our experiments underestimate the extent of reluctant sharing.

${ }^{10}$ Alternatively, nonsharers may derive disutility from social pressure or guilt, when in the sharing environment, like reluctant sharers, but are able to resist the pressure to share. Such "reluctant nonsharers" opt out even if the endowment is identical in both environments, $U(1, w, 0)<U(0, w, 0)$. Neglecting this type of "reluctance" results in its underestimation and makes our estimates of the relevance of sorting more conservative.
} 
This follows from the fact that reluctant sharers opt out of the sharing environment when costless sorting is introduced $\left(w=w^{\prime}\right)$ and the assumption that the costless sorting option does not affect the behavior of willing sharers or of nonsharers.

We next consider how subsidizing entry into the sharing environment $\left(w>w^{\prime}\right)$ influences sorting and sharing behavior. It is straightforward to show that entry into the sharing environment increases in the size of the subsidy $w-w^{\prime}$ : Willing sharers always enter, even when the subsidy is zero. Nonsharers enter at any positive subsidy. And reluctant sharers opt into the sharing environment when $\max _{x \in[0, w]} U(1, x, w-x)>U\left(0, w^{\prime}, 0\right)$. This latter condition is more likely to hold the larger $w$ is, and hence the larger $\max U(1, \cdot, \cdot)$ is. Therefore, we expect larger and larger subsidies to lure more and more reluctant sharers back into the sharing environment.

Our theoretical framework also illustrates that the decision to enter a sharing environment is not necessarily positively related to the portion $a$ that agents share when they are in the sharing environment. Consider, for example, the case in which the relative decrease in endowment $\left(w-w^{\prime}\right) / w\left(\right.$ with $\left.w>w^{\prime}\right)$ that a reluctant sharer accepts to avoid the sharing environment is an increasing function of the amount $a$ she shares when put in the sharing environment, $\left(w-w^{\prime}\right) / w=f(a)$ and $f^{\prime}>0$. This implies that, among reluctant sharers, those who share the most in the sharing environment are also those willing to pay the most to avoid the sharing environment. We refer to this condition as "relative sharing aversion." The most generous reluctant sharers are least willing to enter the environment where sharing is possible. ${ }^{11}$ As a result, reluctant sharers' generosity, conditional on giving, is a negative predictor of their inclination to enter the sharing environment.

In our laboratory experiments, we will test the degree to which the presence of reluctant sharers and sorting opportunities affect the prevalence of sharing (Proposition 1). We also consider, in our second experiment, how subsidized entry into the sharing environment interacts with sharing preferences, i.e., how subsidies affect the composition of and behavior observed in the sharing environment.

\section{Experiment 1: Costless Sorting}

Experiment 1 uses a between-subjects design to compare outcomes in dictator games without and with sorting. We hold the endowment constant $\left(w=w^{\prime}\right)$.

\section{A. Experimental Design}

Experiment 1 was conducted in Barcelona, Spain, and Berkeley, CA with students of the Universitat Pompeu Fabra (UPF), the Universitat Autònoma de Barcelona (UAB), and the University of California, Berkeley. We conducted 16 sessions, 8 in

\footnotetext{
${ }^{11}$ A modified Cobb-Douglas utility function, which allows for utility from sharing for reluctant sharers, also has this property (see Lazear, Malmendier, and Weber 2010). Relative sharing aversion also obtains under the simple assumption that the utility of reluctant sharers is determined solely by their own monetary payoff. Relative sharing aversion is, however, not a logical necessity. For example, a person might be close to indifferent between sharing or not, preferring to avoid sharing, but once in the sharing environment chooses to share a great deal. Another, who detests sharing, might part with only a few pennies in the sharing environment, but bears tremendous embarrassment from doing so. The second might pay more to avoid the sharing environment than the first.
} 
each city, and each lasting 20 to 25 minutes, with an even number of 10 to 36 participants. In total, 336 subjects participated (154 in Barcelona, 182 in Berkeley): 166 subjects ( 83 dictators) in the treatment without sorting and 170 subjects ( 85 dictators) in the treatment with sorting.

Upon arrival, subjects were told that they would receive a participation fee $(€ 5$ in Barcelona $^{12}$ and $\$ 5$ in Berkeley) and that they might earn additional money. Subjects randomly drew participant numbers, which determined their role. One half of the subjects, the recipients, were asked to complete a brief questionnaire, for which they would not receive any additional payment, and to then wait quietly. The other half, the dictators, were located in a separate room and received instructions both in writing and aloud. ${ }^{13}$ These instructions varied by treatment. In some sessions we conducted standard dictator games without sorting, and in the other sessions, we introduced sorting.

No-Sorting Treatment.- In dictator games without sorting, dictators were asked to divide $€ 10$ (Barcelona) or $\$ 10$ (Berkeley) with a randomly and anonymously matched subject in the other room. At the end of the experiment, the experimenter would describe the game to the participants in the other room and show each of them how much money they received. Each dictator received an envelope with a sheet indicating the number of the paired recipient. Dictators wrote their own participant number on the sheet and indicated a division of the endowment in increments of 10 (Barcelona) or 25 (Berkeley) cents. The experimenter then collected the envelopes and asked the dictators to complete the same one-page questionnaire as the recipients.

Sorting Treatment.- In games with sorting, we added an initial stage in which each dictator decided whether to enter the dictator game. We use this choice between a second stage with sharing opportunity (dictator game) and one without sharing opportunity (fixed payment) as a simple, abstract way to represent the decision of whether to sort into an environment in which sharing is possible. Dictators received two envelopes labeled "participate" and "don't participate." If they chose to participate in the dictator game, they were instructed to open the envelope marked "participate," which contained the sheet with the participant number of the paired recipient. They would record their own number and specify a division. If they chose not to participate, they received $\$ 10$ ( $€ 10)$ without the option to divide the money. In that case, they opened the envelope marked "don't participate" (which did not contain a matched participant number) and wrote only their own participant number on the sheet inside. ${ }^{14}$ After collecting the envelopes, the experimenter separated receivers matched with participating and nonparticipating dictators. For those matched with nonparticipating dictators, the experiment ended and these subjects received only the $\$ 5(€ 5)$ participation fee. Those paired with participating dictators received a description of the dictator game, and saw the sheet informing them of how much they had been given by an anonymous dictator.

\footnotetext{
${ }^{12}$ At the time the sessions were conducted, $€ 1$ was worth about $\$ 1.28$.

${ }^{13}$ Instructions and materials for experiments at both locations are in the Appendix. Instructions for Experiment 2 are similar, except for the specified treatment differences. The Barcelona sessions were conducted in Spanish (Castilian), but the instructions are translated into English.

${ }^{14}$ The procedure ensured that subjects participating and not participating wrote roughly the same amount on the sheets, thus preserving anonymity.
} 
The questionnaire, administered in both treatments, asked for detailed demographics. We also asked about social preferences (donations to charity during the past year), risk preferences (like or dislike of risks), and how many people "in the other room" a subject knew. In Berkeley, we added the question "Why did you decide to share (or not share) the amount you did in the experimental task today? If applicable, why did you decide not to participate?"

\section{B. Results}

Experiment 1 allows us to test whether sorting decreases the aggregate amount shared and to infer the relative frequencies of reluctant and willing sharers (Proposition 1). We can also draw inferences about the relative generosity of reluctant and willing sharers.

Figures 1A and 1B show the distributions of amounts shared, and the frequencies of subjects who opt out of the sharing environment, separately for Barcelona and Berkeley. Without sorting, sharing is comparable to previous experiments, $€ 1.87$ on average in Barcelona and \$2.00 in Berkeley. Most subjects share a positive amount (60 percent in Barcelona, 64 percent in Berkeley). However, the introduction of sorting strongly decreases the average amount shared to only $€ 0.58$ in Barcelona and \$1.21 in Berkeley. Both decreases are statistically significant in a nonparametric rank-sum test (Barcelona: $z=3.39, p<0.001$; Berkeley: $z=2.34$, $p=0.02$ ). As predicted, and consistent with previous results, many subjects choose to opt out, 72 percent in Barcelona and 50 percent in Berkeley, with the difference between locations being statistically significant in a nonparametric chi-squared test $\left(\chi^{2}(1)=4.18, p=0.04\right)$.

Our data allows estimating the relative frequencies of the three postulated socialpreference types. Nonsharers are those 35 percent who do not share even in the no-sorting treatment, i.e., the standard dictator game (33 percent in Barcelona, 36 percent in Berkeley). Willing sharers are those 32 percent who share even in the sorting treatment (28 percent in Barcelona, 38 percent in Berkeley). Reluctant sharers make up the remaining 33 percent (39 percent in Barcelona, 26 percent in Berkeley), implicitly sharing in the no-sorting treatment but not in the sorting treatment.

Table 1 confirms the statistical significance of our findings in a linear regression and in a tobit estimation for the percentage of the endowment shared, and in a probit estimation for the frequency of sharing. ${ }^{15}$ Standard errors are robust to

\footnotetext{
${ }^{15}$ The distributions of amounts given in Figures $1 \mathrm{~A}$ and $1 \mathrm{~B}$ suggest a tobit model to account for the $\$ 0$ corner solution. Note that the use of a hurdle model (see Mullahy 1986) to account for the two-step decision-whether to participate and, if participating, how much to give-is not appropriate here. The hurdle model generalizes the tobit model in allowing two separate stochastic processes to determine participation and, conditional on participation, the amount given. However, unlike the data typically analyzed with hurdle models (including previous work related to dictator games, e.g., Erkal, Gangadharan, and Nikiforakis forthcoming), our data contains two distinct processes generating zero sharing: opting out and opting in but sharing zero. A standard hurdle model would treat all zeros as determined by a single binary process. This is, at best, unnecessary since we directly observe the two processes generating zero, and would need to be accounted for by extending the first stage to a bivariate probit. More likely, this approach is problematic since the focus of our experiments is to analyze specifically the effect of allowing for two different types of zeros on the composition of participants in the sharing environment.
} 


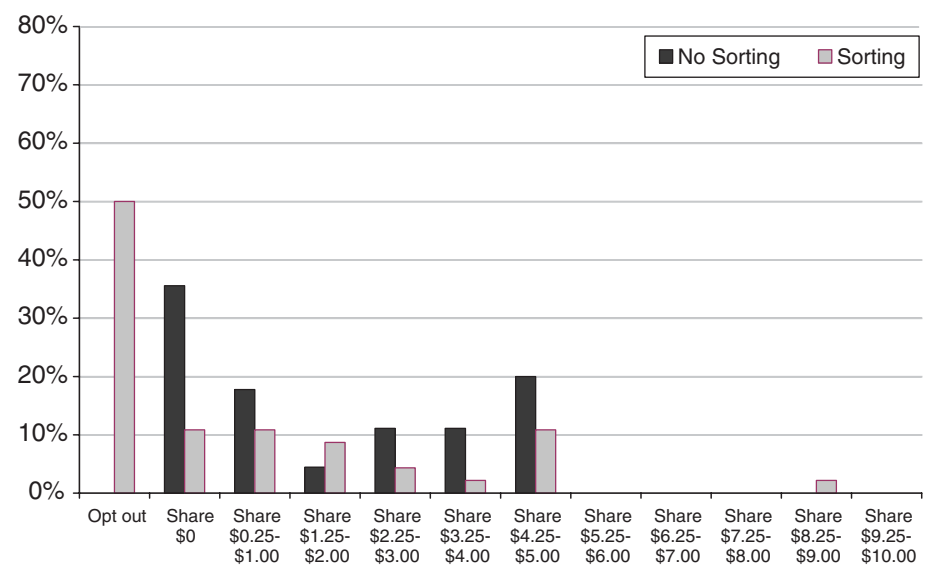

Figure 1A. Distributions of Amounts Shared

(Experiment 1, Berkeley)

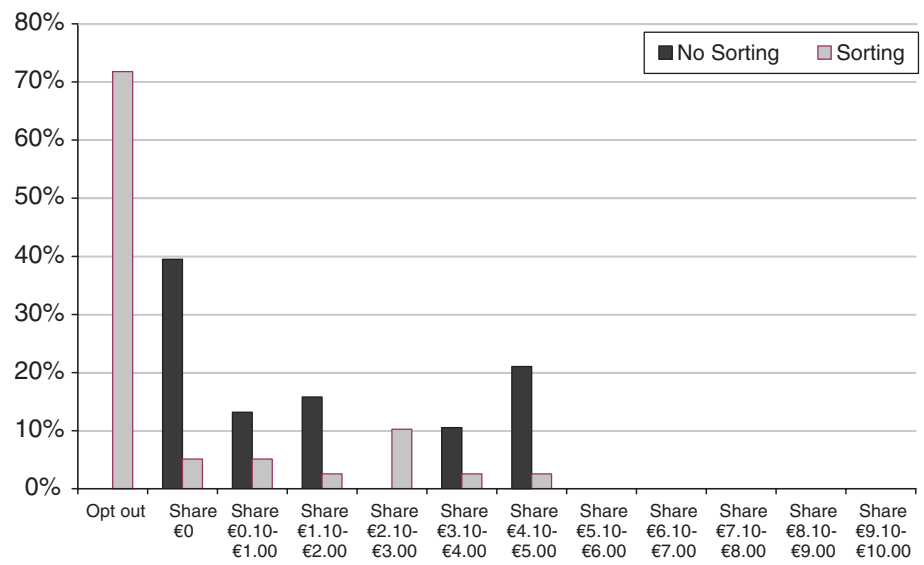

Figure 1B. Distributions of Amounts Shared

(Experiment 1, Barcelona)

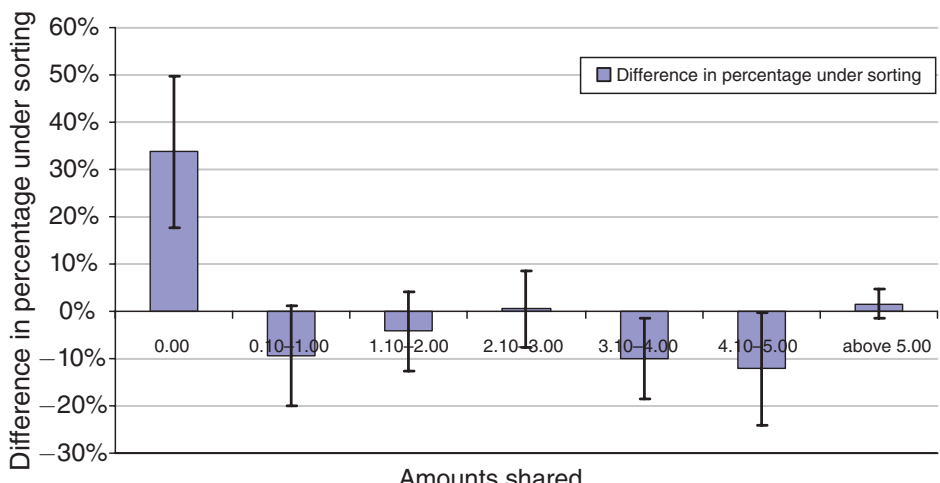

Figure 1C. Distribution of Difference in Amounts Shared (Experiment 1, Berkeley and Barcelona)

Notes: In Figure 1C, coefficient estimates of the sorting indicator and confidence intervals are from linear regressions of indicators for giving bins on the treatment dummy (sorting) and the full set of socio-demographic control variables (see Table 2). Confidence intervals use bias-corrected robust standard errors (HC3). 
TABLE 1-EFFEct of Sorting ON SHARING

\begin{tabular}{|c|c|c|c|c|c|c|}
\hline \multirow[t]{2}{*}{$\begin{array}{l}\text { Model: } \\
\text { Dependent variable: }\end{array}$} & \multicolumn{2}{|c|}{$\begin{array}{c}\text { OLS } \\
\text { Proportion Shared }\end{array}$} & \multicolumn{2}{|c|}{$\begin{array}{c}\text { Tobit } \\
\text { Proportion Shared }\end{array}$} & \multicolumn{2}{|c|}{$\begin{array}{c}\text { Probit } \\
\text { Proportion Shared }\end{array}$} \\
\hline & $(1)$ & $(2)$ & (3) & (4) & $(5)$ & (6) \\
\hline Sorting & $\begin{array}{l}-0.102 * * \\
(0.029)\end{array}$ & $\begin{array}{r}-0.079^{*} \\
(0.043)\end{array}$ & $\begin{array}{c}-0.234 * * * \\
(0.0578)\end{array}$ & $\begin{array}{l}-0.173 * * \\
(0.078)\end{array}$ & $\begin{array}{l}-0.309 * * * \\
(0.073)\end{array}$ & $\begin{array}{l}-0.253 * * \\
(0.102)\end{array}$ \\
\hline Barcelona & & $\begin{array}{c}-0.013 \\
(0.045)\end{array}$ & & $\begin{array}{c}-0.024 \\
(0.074)\end{array}$ & & $\begin{array}{c}-0.041 \\
(0.112)\end{array}$ \\
\hline Sorting $\times$ Barcelona & & $\begin{array}{c}-0.050 \\
(0.058)\end{array}$ & & $\begin{array}{c}-0.145 \\
(0.124)\end{array}$ & & $\begin{array}{c}-0.139 \\
(0.154)\end{array}$ \\
\hline $\begin{array}{l}\text { Observations } \\
\text { (Pseudo-) } R^{2}\end{array}$ & $\begin{array}{c}168 \\
0.070\end{array}$ & $\begin{array}{c}168 \\
0.084\end{array}$ & $\begin{array}{c}168 \\
0.086\end{array}$ & $\begin{array}{c}168 \\
0.107\end{array}$ & $\begin{array}{c}168 \\
0.070\end{array}$ & $\begin{array}{c}168 \\
0.082\end{array}$ \\
\hline
\end{tabular}

Notes: Sorting is a dummy equal to 1 in treatments where subjects can opt out. The dependent variable Proportion Shared is 0 for subjects who opted out. The dependent variable Shared Something is a dummy equal to one if the subject shared a positive amount. The tobit model accounts for 89 observations being left-censored at zero. The probit model estimates are marginal effects. Robust standards are in parentheses (with bias-correction (HC3) in the linear case, see MacKinnon and White 1985) and are calculated using jackknife estimation for the tobit model. Constant included.

*** Significant at the 1 percent level.

** Significant at the 5 percent level.

* Significant at the 10 percent level.

heteroskedasticity and, in the linear regressions, adjusted for small-sample bias. ${ }^{16}$ Under all estimation procedures, sorting significantly reduces sharing, and the effect is similar across cities (insignificantly larger in Barcelona).

In addition, the distributions of giving with and without sorting reveal that many of the givers affected by the sorting option are rather generous. To assess the distributional effects, we estimate seven separate linear regressions with an indicator for each giving bin from Figures $1 \mathrm{~A}$ and $1 \mathrm{~B}$ as the independent variables, and an indicator for sorting as the main explanatory variable. We pool the Berkeley and Barcelona data, neglecting currency differences, and include zero giving after opting out in the 0.00 bin. To maximize efficiency, we control for the full set of socioeconomic survey variables and for the sites Berkeley, Pompeu Fabra, and Autonoma. (The resulting 11 individual characteristics are listed in Table 2.) The coefficient estimates of the Sorting indicator and the 95 percent confidence intervals (using bias-corrected robust standard errors (HC3)) are displayed in Figure 1C. Sorting significantly increases the percentage of subjects giving zero by 33.7 percent. The biggest and most significant negative shifts occur for giving between 3 and 4 ( -10.0 percent, $p$-value $=0.021)$ and between 4 and $5(-12.2$ percent, $p$-value $=0.046) .{ }^{17}$ This

\footnotetext{
${ }^{16}$ Following MacKinnon and White (1985), we use the residual-variance estimator HC3, which approximates a jackknife estimator. Similarly, in the tobit model, we perform a jackknife estimation, which produces slightly more conservative standard errors than the robust variance estimator. If we cluster by session, standard errors in this and in all other estimations are very similar and typically slightly smaller, though unlikely to be reliable given the few clusters (16 sessions in this table, fewer in other estimations).

${ }^{17}$ The reduction in giving between 0 and 1 is also relatively large and marginally significant $(-9.3$ percent, $p$-value $=0.083)$. The results are very similar under various alternative sample splits into different giving bins. For example, if we equalize bin size to 7-8 percent of subjects (other than the large, non-separable bin of subjects giving \$0) and split into $0.00,(0.00-1.00), 1.00,(1.00-2.00],(2.00-3.50],(3.50-4.50]$, and more than 4.50 , the largest significant reductions in sharing come from the bins of 1.00, (3.50-4.50], and more than 4.50. Quantile regressions confirm the same pattern, though they cannot be estimated for the lower quantiles due to the mass point at zero of the dependent variable.
} 
TAble 2-Determinants of Sharing (Experiment 1)

\begin{tabular}{|c|c|c|c|c|}
\hline & (1) & $(2)$ & (3) & $\begin{array}{c}\text { Coefficients of partial } \\
\text { determination }\end{array}$ \\
\hline Sorting & $\begin{array}{l}-0.102 * * * \\
(0.029)\end{array}$ & & $\begin{array}{l}-0.104 * * * \\
(0.033)\end{array}$ & 0.28 \\
\hline Gender: Female & & $\begin{array}{c}-0.010 \\
(0.033)\end{array}$ & $\begin{array}{c}-0.013 \\
(0.032)\end{array}$ & 0.03 \\
\hline Ethnicity: Catalan & & $\begin{array}{c}0.0285 \\
(0.045)\end{array}$ & $\begin{array}{c}0.042 \\
(0.044)\end{array}$ & 0.08 \\
\hline Ethnicity: Asian & & $\begin{array}{c}0.016 \\
(0.058)\end{array}$ & $\begin{array}{c}0.001 \\
(0.057)\end{array}$ & 0.00 \\
\hline Ethnicity: White & & $\begin{array}{c}-0.075 \\
(0.057)\end{array}$ & $\begin{array}{c}-0.074 \\
(0.054)\end{array}$ & 0.10 \\
\hline Socio-economic Status: Middle Class & & $\begin{array}{c}-0.005 \\
(0.039)\end{array}$ & $\begin{array}{c}0.006 \\
(0.038)\end{array}$ & 0.01 \\
\hline Upper to Middle Class & & $\begin{array}{c}-0.006 \\
(0.043)\end{array}$ & $\begin{array}{c}-0.005 \\
(0.043)\end{array}$ & 0.01 \\
\hline Age Group: Graduate Student & & $\begin{array}{r}-0.010 \\
(0.053)\end{array}$ & $\begin{array}{c}-0.012 \\
(0.053)\end{array}$ & 0.02 \\
\hline Major: Business or Economics & & $\begin{array}{r}-0.040 \\
(0.037)\end{array}$ & $\begin{array}{c}-0.036 \\
(0.037)\end{array}$ & 0.09 \\
\hline University: Berkeley & & $\begin{array}{c}0.011 \\
(0.067)\end{array}$ & $\begin{array}{c}0.021 \\
(0.063)\end{array}$ & 0.03 \\
\hline University: Pompeu Fabra & & $\begin{array}{c}-0.065 \\
(0.050)\end{array}$ & $\begin{array}{c}-0.073 \\
(0.049)\end{array}$ & 0.13 \\
\hline Siblings: 0 Siblings & & $\begin{array}{c}0.054 \\
(0.067)\end{array}$ & $\begin{array}{c}0.037 \\
(0.071)\end{array}$ & 0.05 \\
\hline 1 Sibling & & $\begin{array}{l}-0.078 * * \\
(0.037)\end{array}$ & $\begin{array}{l}-0.083 * * \\
(0.035)\end{array}$ & 0.19 \\
\hline 3 or more Siblings & & $\begin{array}{c}-0.047 \\
(0.057)\end{array}$ & $\begin{array}{c}-0.058 \\
(0.055)\end{array}$ & 0.10 \\
\hline Donation (during past year) & & $\begin{array}{c}-0.047 \\
(0.034)\end{array}$ & $\begin{array}{c}-0.033 \\
(0.032)\end{array}$ & 0.08 \\
\hline Risk-seeking & & $\begin{array}{c}0.043 \\
(0.034)\end{array}$ & $\begin{array}{c}0.029 \\
(0.034)\end{array}$ & 0.08 \\
\hline Constant & $\begin{array}{l}0.194 * * * \\
(0.022)\end{array}$ & $\begin{array}{l}0.214 * * * \\
(0.076)\end{array}$ & $\begin{array}{l}0.264 * * * \\
(0.070)\end{array}$ & \\
\hline $\begin{array}{l}\text { Observations } \\
\text { (Adjusted) } R^{2}\end{array}$ & $\begin{array}{l}168 \\
0.07\end{array}$ & $\begin{array}{l}166 \\
0.03\end{array}$ & $\begin{array}{l}166 \\
0.10\end{array}$ & \\
\hline
\end{tabular}

Notes: OLS regressions with Percentage Shared (out of $\$ 10.00$ or $€ 10.00$ endowment) as the dependent variable. Bias-corrected robust standard errors $(\mathrm{HC} 3)$ are in parentheses.

*** Significant at the 1 percent level.

** Significant at the 5 percent level.

* Significant at the 10 percent level.

finding provides evidence that sorting matters even for the subset of relatively generous givers. A large fraction of those who share generously do so reluctantly.

We gauge the importance and robustness of sorting by relating it to other determinants of sharing. Table 2 compares the effect of sorting on the percentage shared (column 1) to the effect of the demographics and self-reported preferences on the percentage shared (column 2) in a simple linear framework, again with bias-corrected robust standard errors. While the effect of sorting is highly significant and large (-10 percent), all other dummy coefficients are smaller in absolute size, and 
only one enters significantly. The results are very similar when including both the sorting dummy and the individual characteristics (column 3). ${ }^{18}$ Overall, sorting is significantly more important than any of the individual characteristics in determining sharing behavior.

A second measure of the importance of sorting is the portion of explained variance. In the regression with only Sorting as the independent variable (column 1), the adjusted $R^{2}$ is 0.07 . In the regression with the 11 individual characteristics (column 2 ), it is only $0.03 .{ }^{19}$ That is, the observable characteristics explain only half as much variance as Sorting alone, once we account for the effect of merely adding predictors. More directly, we calculate the coefficients of partial determination in the regression including both Sorting and demographic dummies, shown to the right of the standard errors in column 3. The partial $R^{2}$ s are calculated, for each predictor $i$, as $\left(R^{2}-R_{(i)}^{2}\right) /\left(1-R_{(i)}^{2}\right)$, where $R_{(i)}^{2}$ is the $R^{2}$ with predictor $i$ removed from the equation. Each individual characteristic explains between 0.00 and 0.19 of the remaining unexplained variance, but Sorting explains 0.28. Thus, the Sorting variable not only has an economically and statistically larger effect, but also is a more reliable predictor of sharing than any other variable. ${ }^{20}$

Overall, Experiment 1 provides evidence that not all sharing is the result of people wanting to share. Instead, reluctant sharers and (some) nonsharers take advantage of the costless sorting option. ${ }^{21}$ Surprisingly, the largest and most significant reductions in giving occur among relatively generous givers, who share $\$ 3-\$ 5$. This finding is a first indication that generosity in sharing does not necessarily imply high utility from sharing, which we explore in more detail in the next experiment.

\section{Experiment 2: Subsidized Sharing}

In Experiment 1, we explored the basic effect of sorting on aggregate sharing. We next introduce price effects to test whether relative prices in the environments with and without sorting affect the differential sorting of individuals with different social preferences. Specifically, we introduce subsidies $\left(w>w^{\prime}\right)$ for entry into the sharing environment and analyze how they influence the choice to (re-)enter the sharing environment.

The main focus is on the reluctant sharers. Since willing sharers enter (and share) whenever $w \geq w^{\prime}$, a subsidy should not change their entry decisions. Nonsharers are indifferent between not entering and entering (and sharing zero) when $w=w^{\prime}$, but

\footnotetext{
${ }^{18}$ All findings are highly robust to alternative regression specifications, such as refinements of the dummies for age, social class, or major (though a higher number of controls risks saturating the model).

${ }^{19}$ The adjusted $R^{2}$ is calculated as $1-\left(1-R^{2}\right) \cdot[(N-1) /(N-K-1)]$, where $N$ is the number of observations and $K$ the number of predictors.

${ }^{20}$ We also check the robustness of the sorting effect across different subgroups of subjects. For each demographic characteristic (subsamples by gender, ethnicity, socio-economic status, age, siblings), including educational choices (major, university), and for the elicited preferences (donations, risk preferences), we calculate the average amount shared in the treatment without sorting and the treatment with sorting. The results are displayed in Figure A1 in the Appendix. In all but one of the 20 subgroups, the average amount shared without sorting (left bars) is lower than the average amount shared with sorting (right bars). Thus, our baseline result is not only robust to the inclusion of individual characteristics as controls, but also pervasive throughout all categorizations by such characteristics.

${ }^{21}$ Among those who chose to enter the dictator game, 21 percent ( 7 of 34) gave nothing to the recipient. This represents 8 percent of the total population, including those who opted out. The existence of such behavior is consistent with our interpretation of "nonsharers" as being indifferent between entering and not entering when $\mathrm{w}=w^{\prime}$.
} 
enter and share nothing whenever $w>w^{\prime}$. Reluctant sharers, instead, view entering and sharing as costly, and therefore their entry decision depends on the size of the subsidy. For example, if their disutility from entry is proportional to some positive function of the amount they share initially (relative sharing aversion), low subsidies will primarily attract those reluctant sharers who share the least. As a result, small subsidies may decrease the average amount shared by entrants.

In order to pin down subjects' types and generosity in sharing, we use a withinsubject design. Each subject first plays the standard dictator game for $\$ 10$ both without and with a sorting option, but no price differential $\left(w=w^{\prime}\right)$. The behavior observed in the two games determines each individual's type. This part of the experiment is a within-subject replication of the two treatments in Experiment 1. Then, subjects play the sorting treatment with increasing subsidies for entry into the dictator game $\left(w>w^{\prime}\right)$. The amount available in the dictator game goes up while the amount available after opting out remains $\$ 10$. The observed response to the increasing subsidies reveals how the sorting behavior of the different types interacts with prices.

The within-subject design also provides a measure of the generosity of different types. The between-subject treatments of Experiment 1 made it difficult to assess whether those who share willingly are more generous than those who share reluctantly since we could not track individuals across environments with and without sorting. Experiment 2 allows us to examine the amounts shared by all types in both the rounds without and the rounds with sorting.

Finally, we also add a no-anonymity treatment, which allows us to explore the robustness of our findings to situations in which dictators are not anonymous but have to face the recipient-as in the many cases in which real-world dictators are directly confronted by someone requesting aid or donations.

\section{A. Experimental Design}

Experiment 2 took place at the Pittsburgh Experimental Economic Laboratory (PEEL). Subjects were graduate and undergraduate students at the University of Pittsburgh and Carnegie Mellon University. We conducted 12 sessions, 6 in each anonymity treatment. A total of 188 subjects participated: 92 (46 dictators) in the no-anonymity treatment and 96 (48 dictators) in the anonymity treatment. ${ }^{22}$

As in Experiment 1, sessions began with subjects being randomly separated into two groups. One half of the participants (recipients) went to a separate room where they completed questionnaires for approximately 20 minutes. The other half of the participants (dictators) were informed that they would make a series of decisions, with new instructions distributed prior to each decision. Payoffs would be based on one decision randomly selected at the end of the experiment. In each decision, the procedure replicated that of Experiment 1, other than changing the dictator game endowment.

\footnotetext{
${ }^{22}$ One subject was accidentally allowed to participate twice (both times as dictator). We omitted this subject's second participation from the data. Since subjects' choices were never revealed to anyone else until the end of the experiment, it is very unlikely that this subject influenced the choices of other dictators in the second session.
} 
Decision 1.-Decision 1 consisted of a dictator game with no sorting. The endowment was $\$ 10$, denoted as 40 tokens. Subjects were told that if Decision 1 were selected to count at the end of the experiment, then the experimenter would describe the dictator game publicly to the other participants, and each recipient would find out how much money he or she had been given. In the no-anonymity treatment, the dictators themselves handed the sheets to the recipients.

Decision 2.--In Decision 2, dictators had the opportunity to play the same dictator game as in Decision 1, with a (potentially) new randomly selected participant. Alternatively, they could choose to "pass" (i.e., not to play the game). The procedure mirrored the sorting treatment in Experiment 1. Dictators had to open one of two envelopes. If they opened the envelope labeled "play," they would see the number of their matched participant, write down their own number, and indicate a division of 40 tokens. If they opened the envelope labeled "pass," they would not see a participant number, but would write down their own number and mark an "X" on the sheet inside. Subjects were told that if they chose to play the game and if Decision 2 were selected to count, then their paired recipient would be informed about the game and the allocation of tokens.

Remaining Decisions.-The remaining three decisions (four in the no-anonymity case) proceeded exactly as Decision 2, with the exception that the dictator-game endowment increased. Table 3 presents the endowment for each decision. ${ }^{23}$

At the end of each session, the experimenter randomly drew one of the decisions to count. Then either all recipients (if Decision 1 was drawn), or only those matched to dictators who decided to play (if Decision 2 or higher was drawn), returned to the main room and were informed about the game and shown the payoff sheet filled out by their matched dictator. In the no-anonymity treatment, the dictators themselves handed the sheets to the recipients. Participants were then paid their earnings and $\$ 6$ participation fee. Unmatched recipients were not informed about the game and were paid $\$ 6$ after completing their questionnaires.

Note that we did not counterbalance the order of the decisions across sessions. The purpose of the within-subject design was to compare the rates of re-entry, under increasing subsidies, within the group of reluctant sharers. In order to be comparable, all subjects had to be exposed to the exact same initial treatment. Among different possible "initial treatments," the above order (starting with the standard dictator game) permits comparisons of the first decision to standard dictator games. However, other "initial treatments" might also be of interest, and the design and results leave open the question whether our classification of social-preference types and their differential sharing behaviors survive different ordering. ${ }^{24}$

\footnotetext{
${ }^{23}$ The number of decisions and endowments differ between anonymity and no-anonymity treatments since an initial pilot session revealed that, under anonymity, almost all subjects play the dictator game once the endowment reaches about $\$ 13$. Since our goal was to explain differences in "re-entry" to the game, we fine-tuned the payoffs to measure such differences. We also decreased the number of rounds to allow the experiment to run more quickly.

${ }^{24}$ Note, however, that variation in the order of Decisions 1 and 2 turned out to be redundant since the outcomes closely replicate the results from the between-subjects experiment. Also note that we do not account, separately, for
} 


\section{B. Results}

The behavior in Decisions 1 and 2 strongly corroborates the findings of the between-subjects design in Experiment 1. When dictators are forced to play the game (Decision 1), 74 percent share. When subjects are given the opportunity to opt out of the game (Decision 2), only 30 percent share. As a result, the average amount shared per subject decreases substantially, from $\$ 2.68$ without sorting (Decision 1) to $\$ 1.19$ when sorting becomes possible (Decision 2).

The impact of sorting is robust to the removal of anonymity. In the standard dictator game (Decision 1), 81 percent share in the no-anonymity treatment and 67 percent in the anonymity treatment. As shown in Table 3, subjects share average amounts of $\$ 2.42$ (anonymity) and \$2.92 (no-anonymity). Thus, the lack of anonymity produces slightly more sharing, but this difference is not statistically significant $\left(t_{92}=1.17\right)$. In the dictator game with sorting (Decision 2), only 25 percent share in the no-anonymity treatment, and 35 percent share in the anonymity treatment. The average amounts shared decrease, to $\$ 1.22$ in anonymity and to $\$ 1.17$ in no-anonymity. Thus, the lack of anonymity makes opting out even more attractive and reduces sharing slightly more, but the difference in amounts is again not significant $\left(t_{92}=0.14\right){ }^{25}$

The results of the first two decisions in Experiment 2 demonstrate the robustness of the sorting effect from Experiment 1, both when we relax anonymity and when we conduct a within-subject test.

Classification of Social-Preference Types.-The within-subject design of Experiment 2 allows a classification of individual subjects into the three posited types. Based on their first two decisions, 23 percent of the subjects are nonsharers-they share nothing in Decision 1 and either opt not to play or share nothing in Decision 2. A slightly larger group, 29 percent, are willing sharers, who share both in Decision 1 and in Decision 2. The largest group, 41 percent, consists of reluctant sharers. They share in Decision 1 and opt out in Decision 2. These three categories account for 95 percent of the subjects. ${ }^{26}$ Compared to Experiment 1, the proportions differ slightly. Here, we

\footnotetext{
learning since several recent studies of repeated dictator games have found little change in behavior over time (Duffy and Kornienko 2005; Hamman, Loewenstein, and Weber 2009), differently from, for example, the case of dominancesolvable games (Rick and Weber 2010). We also analyzed an alternate dataset (Broberg, Ellingsen, and Johannesson 2007), in which subjects first played a dictator game (Decision 1) and then stated a reservation price for exiting the game. Unlike in our data, where we directly observe re-entry into the sharing environment, re-entry in this other experiment is implicit in the reservation price. We confirm our finding that the amount shared is a negative predictor of reluctant individuals' willingness to re-enter. Since the alternate experimental data was collected using different procedures (but never previously analyzed in light of our prediction), the confirmation of our results highlights that the strong compositional effects of sorting and prices are not unique to our experimental procedures. For detail on this reanalysis, see Lazear, Malmendier, and Weber (2010, appendix 2).

${ }^{25}$ Behavior in Decisions 3 and higher does not differ between anonymity treatments either when controlling for endowments. For example, comparing Decision 3 under no-anonymity and Decision 4 under anonymity, both with an endowment of \$11, we find that neither the average amounts shared (\$1.51 and \$1.42) are significantly different $\left(t_{92}=0.20\right)$ nor the frequencies of entry $(z=1.59)$.

${ }^{26}$ Of the remaining five subjects, three shared something in Decision $1(\$ 0.25, \$ 2.50, \$ 5)$ and shared nothing in the remainder of the experiment (but frequently opted to play). We might classify these three subjects as reluctant sharers, though they did not rely on the sorting opportunity. Another subject shared $\$ 2.50$ initially, shared $\$ 0.50$ in Decision 4, and nothing otherwise (but opted to play every time). A final subject shared nothing initially, but then shared $\$ 4$ in all subsequent decisions_-possibly a willing sharer, with noise in the first decision.
} 
Table 3-Average Amounts Shared under Subsidized Sharing (Experiment 2)

\begin{tabular}{|c|c|c|c|c|c|c|c|}
\hline \multirow[b]{2}{*}{$\begin{array}{l}\text { Sorting } \\
\text { option } \\
(\$ 10) \\
\end{array}$} & \multirow[b]{2}{*}{$\begin{array}{l}\text { Endowment } \\
\text { in dictator } \\
\text { game }\end{array}$} & \multicolumn{3}{|c|}{ Anonymity } & \multicolumn{3}{|c|}{ No anonymity } \\
\hline & & Decision & $\begin{array}{c}\text { Average } \\
\text { amount } \\
\text { (percent) } \\
\text { shared }\end{array}$ & $\begin{array}{l}\text { Percent } \\
\text { entering }\end{array}$ & Decision & $\begin{array}{c}\text { Average } \\
\text { amount } \\
\text { (percent) } \\
\text { shared }\end{array}$ & $\begin{array}{l}\text { Percent } \\
\text { entering }\end{array}$ \\
\hline No & $\begin{array}{c}\$ 10.00 \\
(40 \text { tokens) }\end{array}$ & 1 & $\begin{array}{c}\$ 2.42 \\
(24.2 \%)\end{array}$ & $100 \%$ & 1 & $\begin{array}{c}\$ 2.92 \\
(29.2 \%)\end{array}$ & $100 \%$ \\
\hline Yes & $\begin{array}{c}\$ 10.00 \\
(40 \text { tokens })\end{array}$ & 2 & $\begin{array}{c}\$ 1.22 \\
(12.2 \%)\end{array}$ & $46 \%$ & 2 & $\begin{array}{l}\$ 1.17 \\
(11.7 \%)\end{array}$ & $38 \%$ \\
\hline Yes & $\begin{array}{c}\$ 10.50 \\
(42 \text { tokens) }\end{array}$ & 3 & $\begin{array}{l}\$ 1.34 \\
(12.8 \%)\end{array}$ & $57 \%$ & & & \\
\hline Yes & $\begin{array}{c}\$ 11.00 \\
(44 \text { tokens) }\end{array}$ & 4 & $\begin{array}{c}\$ 1.42 \\
(12.9 \%)\end{array}$ & $74 \%$ & 3 & $\begin{array}{c}\$ 1.51 \\
(13.7 \%)\end{array}$ & $58 \%$ \\
\hline Yes & $\begin{array}{c}\$ 12.00 \\
(48 \text { tokens) }\end{array}$ & 5 & $\begin{array}{c}\$ 1.52 \\
(12.7 \%)\end{array}$ & $76 \%$ & & & \\
\hline Yes & $\begin{array}{c}\$ 13.00 \\
(52 \text { tokens) }\end{array}$ & & & & 4 & $\begin{array}{l}\$ 2.07 \\
(15.9 \%)\end{array}$ & $73 \%$ \\
\hline Yes & $\begin{array}{c}\$ 16.00 \\
\text { (64 tokens) }\end{array}$ & & & & 5 & $\begin{array}{l}\$ 3.21 \\
(20 \%)\end{array}$ & $90 \%$ \\
\hline Yes & $\begin{array}{c}\$ 20.00 \\
(80 \text { tokens })\end{array}$ & & & & 6 & $\begin{array}{l}\$ 4.53 \\
(22.7 \%)\end{array}$ & $100 \%$ \\
\hline Number & sions & & 6 & & & 6 & \\
\hline $\begin{array}{r}\text { Number } \\
\text { (dicta }\end{array}$ & jects & & $\begin{array}{c}92 \\
(46)\end{array}$ & & & $\begin{array}{c}96 \\
(48)\end{array}$ & \\
\hline
\end{tabular}

Note: All averages are unconditional, i.e., subjects who opted out are included (as sharing \$0).

have fewer nonsharers and more reluctant sharers. The distributions of types do not differ significantly by anonymity $\left(\chi^{2}(2)=3.49, p=0.18\right) .{ }^{27}$

Given the above classification, we can determine which type-willing sharers or reluctant sharers-behaves most generously in the dictator game. Recall that the average amount shared conditional on entry in Experiment 1 was slightly higher under sorting, but the between-subject design did not allow calculation of the unconditional sharing of both types. Experiment 2 reveals that the average amount shared (in Decision 1 without sorting) is $\$ 4.46$ for willing sharers ( $\$ 4.22$ under anonymity and $\$ 4.77$ under no-anonymity) and $\$ 3.10$ for reluctant sharers $(\$ 3.20$ under anonymity and $\$ 3.04$ under no-anonymity). The difference is significant at the $p<0.001$ level $\left(t_{64}=3.95\right)$. Thus, those who share willingly, i.e., even when they can avoid the sharing environment, are, on average, significantly more generous

\footnotetext{
${ }^{27}$ Males are more likely to be nonsharers than women (M: 30 percent; F: 20 percent) and less likely to be reluctant sharers (M: 30 percent; F: 47 percent). However, the difference in distributions of types by gender is not statistically significant $\left(\chi^{2}(2)=1.97, p=0.37\right)$.
} 
than those who share reluctantly, a finding confirmed in the door-to-door fundraising field experiment in DellaVigna, List, and Malmendier (forthcoming).

\section{Compositional Effect: Who Do Subsidies Attract into the Sharing Environment?-} The principal issue addressed by Experiment 2 is how subsidizing entry into the sharing environment influences the sorting of different types. Willing sharers, by definition, enter the sharing environment when there is no subsidy $\left(w=w^{\prime}\right)$ and should continue to enter if there is a subsidy $\left(w>w^{\prime}\right)$. In fact, we find that, in Decisions 3 and up, when the sharing environment is subsidized, willing sharers enter the sharing environment 90 percent of the time. ${ }^{28}$ Upon entering, they share significant amounts, at least $\$ 3.82$ on average for every endowment level.

Nonsharers, by definition, share nothing in Decision 2 when $w=w^{\prime}$, mostly by opting out (70 percent). We predicted that those nonsharers who opt out re-enter when the sharing environment is subsidized. In Decisions 3 and beyond, nonsharers enter the sharing environment 78 percent of the time. ${ }^{29}$ As expected, they share very little when they enter, never more than $\$ 0.17$, on average, for any dictator game endowment.

Most important is the behavior of reluctant sharers. Table 4 reports the marginal effects from probit estimations with subjects' decisions to play (1) or to pass (0) as the dependent variable. Since all subjects had to play the game in Decision 1 and since the choice to pass in Decision 2 is used to construct the types, we exclude these two decisions from the analysis. We control for the endowment in each round. ${ }^{30}$

Column 1 explores the relative entry frequencies of the three different types. We exclude the five subjects who did not fit the classification scheme. The omitted category, willing sharers, enters at a significantly higher rate than nonsharers (15 percent more often) and than reluctant sharers (35 percent more often). The difference between nonsharers and reluctant sharers is statistically significant $\left(\chi^{2}(1)=13.89\right.$, $p<0.001)$. As predicted, reluctant sharers are the least willing to re-enter the sharing environment as entry becomes subsidized.

Most interestingly, we also conjectured that those most likely to enter would be those reluctant sharers who share the least initially. Figures 2A and 2B show the frequencies with which different subgroups of reluctant sharers re-enter the sharing environment as the subsidy increases across decisions. We split reluctant sharers into three groups, based on how much they shared in Decision 1. Consistent with our prediction, those who re-enter first are those who shared the least in Decision 1. For example, those who shared only $\$ 1.25$ or less in Decision 1 all re-enter the game by Decision 4 in both treatments, while those who shared more require greater subsidies to re-enter. In fact, for every decision, across both treatments, the highest entry frequency is for those who shared the least initially. Thus, for the subgroup of reluctant sharers, generosity in sharing turns out to be a negative predictor of entry into the sharing environment.

\footnotetext{
${ }^{28}$ As the percentage is below 100, our classification is imperfect. Two participants account for most of the exceptions. They shared positive amounts in Decisions 1 and 2 (and were thus classified as willing sharers), but opted out in every remaining Decision.

${ }^{29}$ Entry among nonsharers increased with the size of the endowment in the game. For example, 61 percent entered in Decision 3, but more than 83 percent did so for all subsequent decisions. This reluctance to enter at low subsidies perhaps indicates that, as we discussed above, some nonsharers experience disutility from sharing nothing in the game-not enough to lead them to share, but enough to induce opting out and even foregoing a (low) subsidy.

${ }^{30}$ The results in the table are substantively unchanged when we also control for treatment, gender, and decision.
} 
TABle 4-Determinants of Entry into Sharing ENVIRONMENT

(Experiment 2, excluding decisions 1 and 2)

\begin{tabular}{|c|c|c|c|c|c|}
\hline \multirow[t]{2}{*}{ Sample: } & \multirow{2}{*}{$\begin{array}{c}\text { All classified } \\
\text { subject } \\
(1)\end{array}$} & \multicolumn{3}{|c|}{ Willing and reluctant sharers } & \multirow{2}{*}{$\begin{array}{c}\text { Reluctant } \\
\text { sharers } \\
(5)\end{array}$} \\
\hline & & (2) & (3) & (4) & \\
\hline Initial proportion shared & & $\begin{array}{c}0.003 \\
(0.175)\end{array}$ & $\begin{array}{l}-0.502 * * * \\
(0.182)\end{array}$ & $\begin{array}{c}0.282 \\
(0.417)\end{array}$ & $\begin{array}{l}-0.823 * * * \\
(0.265)\end{array}$ \\
\hline Nonsharers & $\begin{array}{c}-0.154 * * \\
(0.077)\end{array}$ & & & & \\
\hline Reluctant sharers & $\begin{array}{l}-0.346^{* * * *} \\
(0.060)\end{array}$ & & $\begin{array}{l}-0.350 * * * \\
(0.052)\end{array}$ & $\begin{array}{l}-0.025 \\
(0.196)\end{array}$ & \\
\hline $\begin{array}{l}\text { Initial prop. shared } \times \\
\text { reluctant sharers }\end{array}$ & & & & $\begin{array}{c}-0.882 * \\
(0.460)\end{array}$ & \\
\hline $\begin{array}{l}\text { Endowment in dictator } \\
\text { game }\end{array}$ & $\begin{array}{l}0.068^{* * * *} \\
(0.009)\end{array}$ & $\begin{array}{l}0.059 * * * \\
(0.010)\end{array}$ & $\begin{array}{l}0.067 * * * \\
(0.010)\end{array}$ & $\begin{array}{l}0.066^{* * * *} \\
(0.010)\end{array}$ & $\begin{array}{l}0.086^{* * * *} \\
(0.014)\end{array}$ \\
\hline Observations & 312 & 234 & 234 & 234 & 141 \\
\hline Pseudo- $R^{2}$ & 0.228 & 0.113 & 0.270 & 0.279 & 0.223 \\
\hline
\end{tabular}

Notes: The table reports marginal effects of probit estimations. The dependent variable is an indicator equal to one if the subject shared any positive amount. Robust standard errors are in parentheses.

*** Significant at the 1 percent level.

** Significant at the 5 percent level.

* Significant at the 10 percent level.

Columns 2-5 of Table 4 test the statistical significance of the relationship between entry and (initial) generosity in sharing. Column 2 shows that, taking willing and reluctant sharers together, there is no relation between initial proportion shared and entry. Column 3, however, reveals both that reluctant sharers enter at lower frequency and that there is a significantly negative relationship between entry and initial proportion shared among reluctant sharers. This negative relationship appears to be driven by reluctant sharers who shared a lot initially (column 4): The interaction of initial proportion shared and classification as a reluctant sharer is significant, while the level effect of the initial proportion shared reverts back to being insignificantly positive. Column 5 shows this more directly. If we restrict the sample to reluctant sharers, we find a strong negative relationship between the amount shared initially and entry into the sharing environment. The coefficient of Initial proportion shared indicates that for every additional percentage unit of the endowment shared in Decision 1, reluctant sharers are 0.82 percent less likely to enter the sharing environment. Thus, a reluctant sharer who initially shared $\$ 5$ is roughly 33 percent (i.e., 0.82 . 40 percentage units) less likely to enter than one who shared $\$ 1$.

Overall, we find strong support for our conjecture that generosity in sharing is not a good predictor of utility from sharing. Subsidized entry by reluctant sharers is inversely proportional to the amount they share if the sharing environment is unavoidable (relative sharing aversion).

How Large Are The Compositional Effects?-We have found that a subsidized sharing environment attracts foremost those subjects who are least willing to share-nonsharers and the least generous reluctant sharers. The economic magnitude of the differential sorting effect is large. For example, in Decision 2, when 


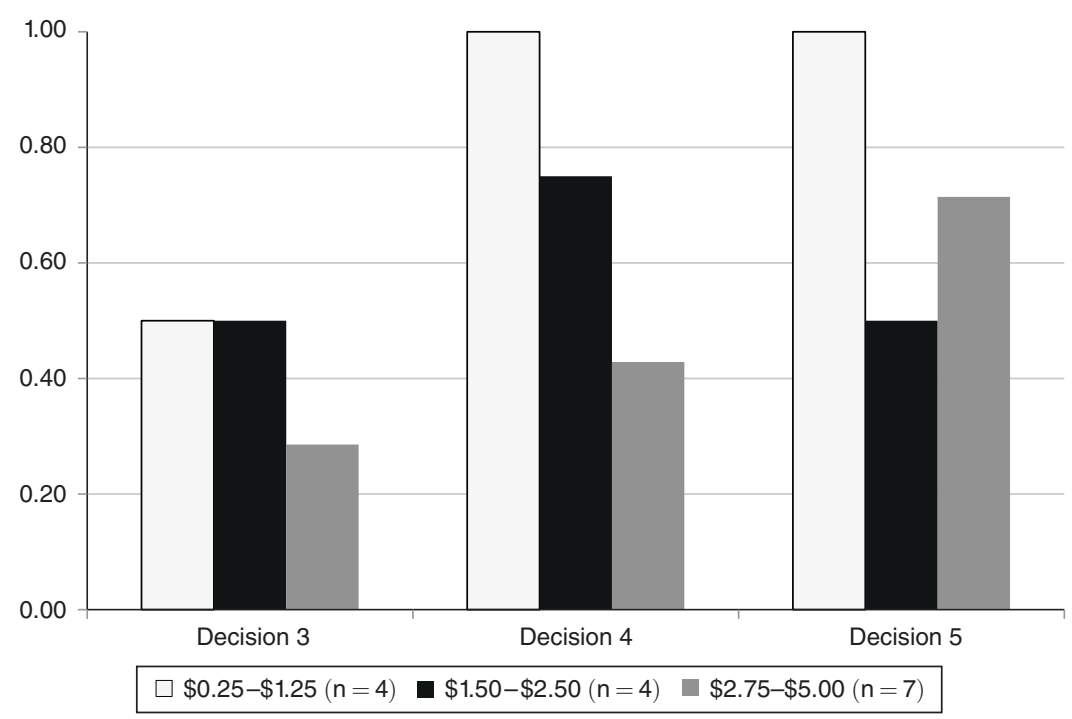

Figure 2A. Proportion of Reluctant Sharers Choosing to Enter by Decision and Initial Amount Shared (Anonymity)

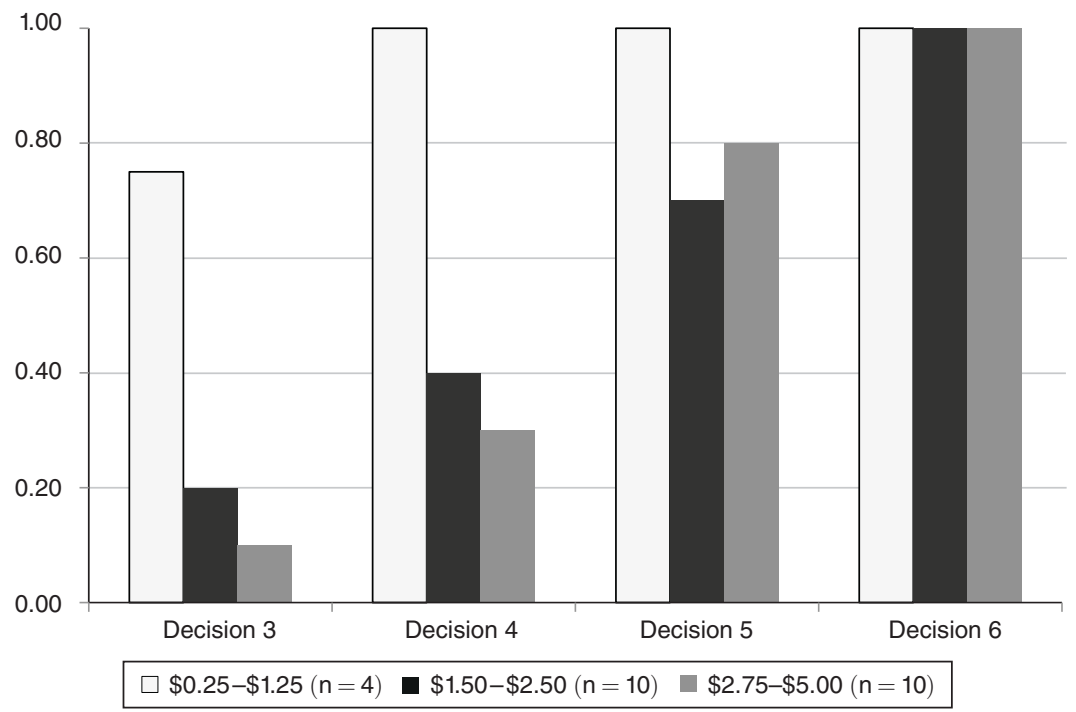

Figure 2B. Proportion of Reluctant Sharers Choosing to Enter By Decision and Initial Amount Shared (No anonymity)

sorting is costless, the average amount shared by those who enter the sharing environment is $\$ 2.88$ ( $\$ 2.68$ with anonymity and $\$ 3.11$ without), a small increase relative to the $\$ 2.68$ (\$2.42 with anonymity and $\$ 2.92$ without) in Decision 1 , when everyone was required to enter, and similar to what we observed for Experiment 1. But when there is a $\$ 1$ subsidy for entering (Decision 4 with anonymity and Decision 3 without), the average amount shared by those who enter decreases to 
$\$ 2.22$ (\$1.92 with anonymity and $\$ 2.59$ without). In fact, for every subsidy level below $\$ 6$, the average amount shared conditional on entry is lower than when there is no subsidy.

A possible concern about this large raw effect of sorting is that it may reflect influences other than the differential sorting of different social-preference types. For example, our design decision to use an increasing endowment or general round effects may affect our results. In order to distinguish these and other unspecified confounds from the compositional effect of differential sorting, we estimate the effect of mere sorting under two "hypothetical sharing rules" that impose some consistency on sharing behavior. One hypothetical sharing rule is that individuals always share the same proportion of the endowment as they did in Decision 1, if they decide to enter. This assumption amounts to individuals proportionally sharing the subsidy. An alternative hypothetical sharing rule is that individuals always share the same absolute amount as in Decision 1, conditional on entry. This assumption amounts to individuals fully pocketing the subsidy. These two hypothetical sharing rules provide bounds that accurately describe 74 percent of the actual choices made by those entering the sharing environment in our experiment.

Table 5 estimates the magnitude of the compositional sorting effect under these two hypothetical sharing rules. For comparison, we show the estimations using the actual amount shared as the dependent variable in columns 1 (OLS) and 2 (tobit). We then show the estimations using the predicted amount if individuals shared the same proportion of the endowment as in Decision 1 (columns 3 and 4) or the same absolute amount as in Decision 1 (columns 5 and 6). (We use amounts rather than proportions as dependent variables to more clearly illustrate the monetary consequences of selective sorting.) We regress each of these dependent variables on three explanatory variables: "Sorting Option," a binary variable equal to one in all rounds with a sorting option (Decisions 2-6); "Presence of Subsidy," a binary variable equal to one in all rounds with subsidies (Decisions 3-6); and "Amount of Subsidy" ( $\$ 0.50$ to $\$ 10.00$, see Table 5). Standard errors are clustered by subject.

The coefficient estimate of Sorting Option under the two hypothetical sharing rules measures the difference in sharing between willing and reluctant sharers. The positive coefficient indicates that those who enter the sharing environment in Decision 2 (willing sharers) share more, on average, than those who opt out when it is costless to do so (reluctant sharers). ${ }^{31}$

The coefficient for Presence of Subsidy is significantly negative and similar in magnitude under all three sharing rules, both in the OLS estimations and in the tobit estimations. The OLS estimates indicate that the presence of a subsidy decreases conditional amounts shared by about $\$ 0.90$, controlling for the amount of the subsidy. However, the coefficients for Amount of Subsidy reveal that each dollar of subsidy increases sharing amounts, by between $\$ 0.05$ and $\$ 0.35$ for the Predicted amount shared. Hence, a small subsidy (e.g., $\$ 1$ or $\$ 2$ ) results in lower average

\footnotetext{
${ }^{31}$ The fact that the coefficient is smaller in magnitude and in statistical significance for the actual amount than for the two hypothetical amounts indicates that willing sharers decreased the amount they shared between Decisions 1 and 2 . This could reflect, among other possibilities, a weakened motivation to share when one knows that one could have avoided the sharing environment altogether.
} 
Table 5-EFfects of Sorting and Subsidies on Conditional Sharing: Actual and Hypothetical Sharing Rules (Experiment 2)

\begin{tabular}{|c|c|c|c|c|c|c|}
\hline \multirow[t]{2}{*}{ Dependent variable: } & \multicolumn{2}{|c|}{$\begin{array}{c}\text { Actual } \\
\text { amount shared }\end{array}$} & \multicolumn{2}{|c|}{$\begin{array}{l}\text { Predicted amount shared } \\
\text { (fixed proportion) }\end{array}$} & \multicolumn{2}{|c|}{$\begin{array}{l}\text { Predicted amount shared } \\
\text { (fixed amount) }\end{array}$} \\
\hline & $\begin{array}{l}\text { OLS } \\
(1)\end{array}$ & $\begin{array}{l}\text { Tobit } \\
(2)\end{array}$ & $\begin{array}{l}\text { OLS } \\
(3)\end{array}$ & $\begin{array}{l}\text { Tobit } \\
(4)\end{array}$ & $\begin{array}{l}\text { OLS } \\
(5)\end{array}$ & $\begin{array}{c}\text { Tobit } \\
(6)\end{array}$ \\
\hline $\begin{array}{l}\text { Sorting Option } \\
\quad \text { (Decisions 2-6) }\end{array}$ & $\begin{array}{c}0.200 \\
(0.293)\end{array}$ & $\begin{array}{c}0.153 \\
(0.450)\end{array}$ & $\begin{array}{l}0.674 * * * \\
(0.253)\end{array}$ & $\begin{array}{l}0.815^{* *} \\
(0.350)\end{array}$ & $\begin{array}{l}0.674 * * * \\
(0.253)\end{array}$ & $\begin{array}{l}0.779 * * \\
(0.320)\end{array}$ \\
\hline $\begin{array}{l}\text { Presence of Subsidy } \\
\quad \text { (Decisions 3-6) }\end{array}$ & $\begin{array}{c}-0.941 * * * \\
(0.263)\end{array}$ & $\begin{array}{l}-1.134 * * * \\
(0.374)\end{array}$ & $\begin{array}{c}-0.955^{* * *} \\
(0.270)\end{array}$ & $\begin{array}{l}-1.214 * * * \\
(0.377)\end{array}$ & $\begin{array}{l}-0.894 * * * \\
(0.253)\end{array}$ & $\begin{array}{l}-1.096^{* * * *} \\
(0.329)\end{array}$ \\
\hline Amount of Subsidy & $\begin{array}{l}0.260 * * * \\
(0.065)\end{array}$ & $\begin{array}{l}0.288 * * * \\
(0.082)\end{array}$ & $\begin{array}{l}0.350 * * * \\
(0.065)\end{array}$ & $\begin{array}{l}0.391 * * * \\
(0.078)\end{array}$ & $\begin{array}{c}0.052 \\
(0.041)\end{array}$ & $\begin{array}{c}0.075 \\
(0.054)\end{array}$ \\
\hline Constant & $\begin{array}{l}2.678 * * * \\
(0.214)\end{array}$ & $\begin{array}{l}2.122 * * * \\
(0.341)\end{array}$ & $\begin{array}{l}2.678 * * * \\
(0.214)\end{array}$ & $\begin{array}{l}2.156 * * * \\
(0.351)\end{array}$ & $\begin{array}{l}2.678 * * * \\
(0.214)\end{array}$ & $\begin{array}{l}2.305 * * * \\
(0.313)\end{array}$ \\
\hline $\begin{array}{l}\text { Observations } \\
\text { (pseudo) } R^{2}\end{array}$ & $\begin{array}{c}382 \\
0.072\end{array}$ & $\begin{array}{c}382 \\
0.011\end{array}$ & $\begin{array}{c}382 \\
0.143\end{array}$ & $\begin{array}{c}382 \\
0.024\end{array}$ & $\begin{array}{c}382 \\
0.015\end{array}$ & $\begin{array}{c}382 \\
0.003\end{array}$ \\
\hline
\end{tabular}

Notes: Robust standard (errors clustered by subject) are in parentheses. The tobit model accounts for 114 observations being left-censored at 0 in column 2, and 96 observations in columns 4 and 6.

*** Significant at the 1 percent level.

** Significant at the 5 percent level.

* Significant at the 10 percent level

amounts shared in the dictator game in all models. While the net negative effect in the first model (actual amount shared) could be influenced by people changing how much they share conditional on entry, Models 2 and 3 show that sorting alone has the same effect.

To summarize, we find that, as in Experiment 1, the presence of a sorting opportunity significantly decreases sharing. We also find that who sorts into and out of the sharing environment is determined by the interaction of prices and social preferences. Subsidizing entry into the sharing environment primarily attracts those who share the least. As a result the net effect of subsidies is decreased sharing, on average, conditional on entry.

In research not reported here (see Lazear, Malmendier, and Weber 2010), we also consider what happens when one makes entry into the sharing environment costly, relative to the environment in which sharing is not possible $\left(w<w^{\prime}\right)$. Here, we observed very little entry into the sharing environment $(22$ percent of subjects enter), i.e., only a subset of willing sharers pay to have the opportunity to share. However, among those who do sort into the sharing environment, the mean amount shared is quite high $(\$ 3.50)$. Therefore, while Experiment 2 shows that subsidized entry into the sharing environment attracts primarily those who share the least, this other study finds that costly entry into the sharing environment results in entry by those who tend to be the most generous. ${ }^{32}$

\footnotetext{
${ }^{32}$ We also find both of these patterns - that subsidized entry primarily attracts those who share the least and that costly entry primarily attracts those who share the most-in a novel re-analysis of Broberg, Ellingsen, and Johannesson (2007) data. For details, see Lazear, Malmendier, and Weber (2010).
} 


\section{Discussion and Conclusion}

People regularly sort into and out of economic environments. Their decision to enter into a particular environment is based on relative prices and governed by individual preferences. As a consequence of this endogenous selection, real-world outcomes can look very different from those based on experiments that capture the behavior of the typical individual in the (subject) population, rather than that of the typical individual who sorts into a particular economic environment.

Although a large literature in economics analyzes endogenous selection theoretically and empirically, there has been less emphasis on its role in the context of social preferences. Much of the literature on social preferences builds on laboratory findings that demonstrate the prevalence and significance of social preferences. But in the typical laboratory experiment, subjects are unaware of what the experiment is about at the time they are recruited. They are placed in one particular situation and have to make choices that they might avoid making outside the laboratory. Thus, opting into and out of these choice environments does not typically occur in the laboratory in the way that it does in the field.

The goal of our analysis is to model the influence of sorting in the context of social preferences. We introduce sorting into the dictator game, which is a common laboratory framework for measuring sharing and social preferences. We allow subjects to select between an environment with a sharing opportunity-the standard dictator game - and an environment in which sharing is not possible-the potential dictator receives money without being asked to share, and the recipient is unaware of any potential sharing. This reflects the kinds of sorting opportunities that economic agents encounter in the real world, where the opportunity to share can often be avoided.

Our first key finding is that most individuals who share when they cannot avoid the sharing situation would prefer to opt out and not to share. This implies the presence of "reluctant sharers," which account for 33 to 41 percent of all subjects in our experiments. This contrasts with 29 to 32 percent that we classify as "willing sharers," who share both when they do and do not have the opportunity to sort out of the sharing environment.

Our second key finding is that prices affect different types of social preferences differently and, hence, alter the composition of the sharing environment. Subsidizing entry into the sharing environment attracts people who share little, relative to when there is no subsidy, thereby leading to lower (conditional) average amounts shared in the sharing environment. Thus, sorting not only affects how many individuals share, but who chooses to do so.

Our work provides an example of how the laboratory can be used to systematically study the responsiveness of different types to varying sorting options. The results also have immediate implications for a variety of real-world sharing situations, in which individuals can decide whether or not to place themselves in environments where sharing is possible. Such contexts include charitable giving, blood donation, disaster relief, and responses to survey requests. Our findings illustrate that giving behavior can vary vastly depending on sorting opportunities, e.g., in a door-to-door fundraiser versus canvassing on the street, since the population reached is likely to feature different social preferences. 


\section{APPENDiX: SAMPLE INSTRUCTIONS FOR EXPERIMENT 1}

(Between-Subjects Design)

The text in brackets and in italics appears only in treatments with a sorting option.

\section{General Instructions}

Thank you for attending the experiment. The purpose of this session is to study how people make decisions. During the session, you are not permitted to talk or communicate with the other participants. If you have a question, please raise your hand and I will come to answer it.

During the session you will earn money. Everyone will receive $€ 5$ for their participation, which will be the minimum compensation for everyone. In addition, there exists a possibility that some may earn more money. At the end of the session the quantity that you have earned will be paid to you in cash. The payments are confidential; we will not inform any of the other participants of the quantity that you earn.

In a moment, you will receive an envelope. Once everyone has received an envelope, you may open it and you will see a card with a number. This is your identification number for the experiment. After looking at it, please keep this number since it will be used during the experiment. This number is private and should not be shared with anybody else.

In a moment, I will ask that all of the participants with even numbers, meaning 2, 4, 6, 8, etc., follow me outside this room. These participants will go to an adjacent area, where they will complete a brief questionnaire, and will receive the $€ 5$ payment from the experimenter for their participation. When leaving the room, please take all of your belongings.

\section{Instructions for participants with odd numbers}

In this experiment, each of you will [decide whether to participate or not] participate in an activity. [That is, participating in the activity is optional.] The activity is the following:

The activity: You will be paired with one of the participants who just left this room. That is, each of you will be paired with one of the participants with an even number $(2,4,6, \ldots)$. The pairings will be made randomly and anonymously, which means that nobody will know the identity of the person with whom he or she is paired. You will have to decide how to distribute $€ 10$ between yourself and the person with whom you are paired. That is, you will decide how much money, between $€ 0.00$ and $€ 10.00$, to give to the other person and how much to keep for yourself. For example, you may decide to give $€ 9.00$ to the other person and keep $€ 1.00$ for yourself, or you may instead decide to give $€ 1.00$ to the other person and keep $€ 9.00$ for yourself. You may select any distribution of the $€ 10$ between yourself and the other person, in increments of $€ 0.10$. The assigned amounts will be paid to you and to the other person (in addition to the $€ 5$ for participation).

Are there questions about the activity? 
The participants in the adjacent area do not know anything about this activity. They received a questionnaire and were asked to complete it.

[You must decide whether to participate or not participate in the activity.

- If you opt to participate in the activity, you will be paired with one of the other participants and will distribute the $€ 10$ between yourself and this participant.] At the conclusion of the session the participant with whom you are paired will re-enter this room and I will explain the activity to him or her. This participant will then discover how much money he or she received from you and how much you kept for yourself. You and the other participant will receive these quantities, plus the $€ 5$ for participation.

- If you opt not to participate in the activity you will not be paired with any other participant and you will not distribute any money. In this case you will receive a fixed amount of $€ 10$ (plus the $€ 5$ for participation), but you will not have the option to distribute this money. At the conclusion of the session, I will go to the adjacent area and I will pay $€ 5$ to the people who are not paired with anyone in this room. These people will not receive any information about the activity.]

This session will now proceed as follows:

1) Each of you has an envelope [...two envelopes: one labeled "participate" and another "don't participate"]. Please do not open this envelope [either envelope] yet.

2) [If you decide to not participate in the activity, you will open the envelope labeled "don't participate." Inside this envelope is a sheet. Once you open the envelope, you will remove the sheet and write your participant number in the indicated space. You will receive $€ 10$.

3) If you decide to participate in the activity, you will open the envelope labeled "participate."] Inside the envelope is a sheet with the number of the participant with whom you are paired and on which you will indicate how to distribute the $€ 10$ between the other person and yourself. Once you open the envelope, you will remove the sheet and will write your participant number in the indicated space. In addition you should look over the sheet to see the number of the participant with whom you are paired. You should then indicate how you wish to distribute the $€ 10$ between the other participant and yourself. The total of the two quantities should sum to exactly 10.00. If they do not sum to 10.00 , then the other participant will receive the amount that you specify and you will receive the remainder.

4) [In either case, $]$ Once you finish, place the sheet back in the envelope and I will collect the envelopes. 
At the end of the session, we will do the following:

5) The experimenter will go to the adjacent area and will bring the other participants. [... only those participants who are paired with someone who opted to participate in the activity. The rest of the participants in the adjacent area will not be paired, will receive the $€ 5$ for their participation and for them the experiment will have concluded.

6) If you opted to participate in the activity, the participant with whom you are paired will reenter this room and will ... ] These participants will receive a brief explanation of the activity. The participant with whom you are paired will receive the sheet that you completed, indicating how much money he or she received from you, out of the $€ 10$.

7) The experimenter will then anonymously pay the other participants [who are paired with someone in this room] their total earnings, and will then pay you anonymously. This will conclude the experiment.

Are there questions? Once we answer any questions we will proceed to open the envelopes. [Please open only one of the two envelopes.]

\section{Decision sheet}

Number of the person with whom you are paired:

Your number (please write your number in the space on the right):

Amount of money to give to the other person:

(in $€ 0.10$ increments)

Amount of money to keep for yourself:

(in $€ 0.10$ increments)
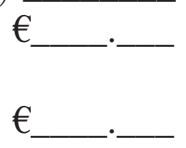

(These two quantities must sum to $€ 10.00$ )

\section{Decision sheet}

You have opted to not participate in the activity. You will not be paired with another participant. At the end of the session, you will receive $€ 10$ plus the $€ 5$ for participation.

Your number (please write your number in the space on the right):

\section{Instructions for participants with even numbers}

During the next few minutes, please complete the questionnaire on the attached sheet. After finishing, please wait a few minutes quietly for me to return. At that time, I will pay you the $€ 5$. In addition, it is possible that I will require the participation of some of you for a brief additional activity in the session. 
While you wait, you may complete the payment receipt. Please leave the amount blank.

\section{Final information for participants with even numbers}

While you were out of this room, [some of] the participants here participated in an activity in which they distributed $€ 10$ between themselves and one of you. You are paired with one of these participants. This other participant decided how much money, from $€ 0.00$ to $€ 10.00$, to give to you and how much to keep for him- or herself. In a moment you will see a sheet on which this participant has indicated how much money to give to you. This amount, along with the $€ 5$ for participation, will be your payment for this session.
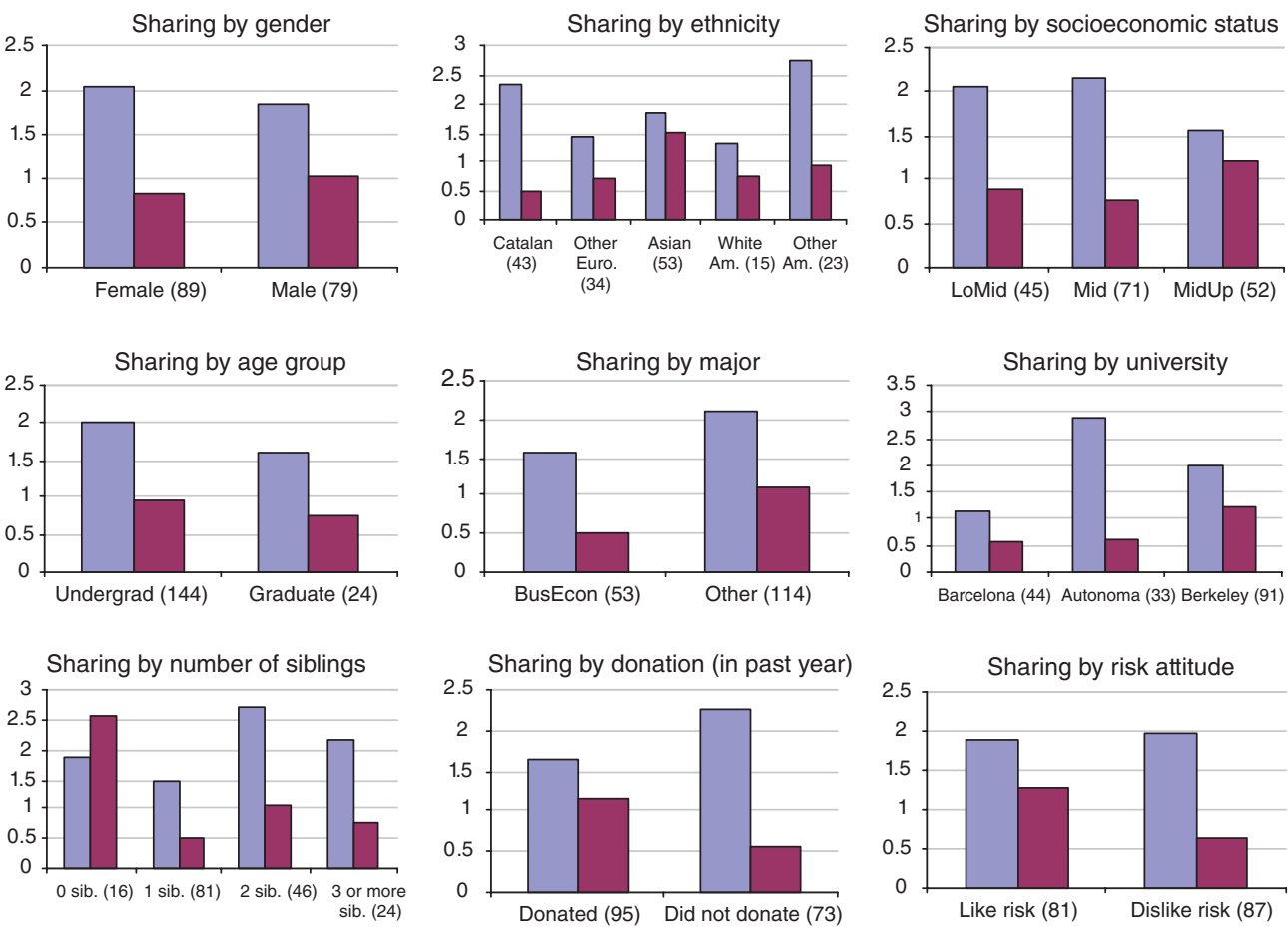

Figure A1. Sharing by SubSample (Experiment 1)

Notes: Sharing by subsamples based on demographics and elicited preferences. The number in parentheses next to each subgroup indicates the number of dictators. The left bar in each subgroup indicates the average amount shared in the treatment without sorting; the right bar indicates the average amount shared with sorting.

\section{REFERENCES}

Ahn, T. K., R. Mark Isaac, and Timothy C. Salmon. 2008. “Endogenous Group Formation.” Journal of Public Economic Theory, 10(2): 171-94.

Andreoni, James. 1989. "Giving with Impure Altruism: Applications to Charity and Ricardian Equivalence." Journal of Political Economy, 97(6): 1447-58. 
Andreoni, James. 1990. "Impure Altruism and Donations to Public Goods: A Theory of Warm-Glow Giving?" Economic Journal, 100(401): 464-77.

Andreoni, James. 2006. "Philanthropy." In Handbook of the Economics of Giving, Altruism, and Reciprocity, Vol. 2, ed. Serge-Christophe Kolm and Jean Mercier Ythier, 1201-70. Amsterdam: North Holland.

Bartling, Björn, Ernst Fehr, Michel André Maréchal, and Daniel Schunk. 2009. "Egalitarianism and Competitiveness." American Economic Review, 99(2): 93-98.

Battigalli, Pierpaolo, and Martin Dufwenberg. 2007. "Guilt in Games." American Economic Review, 97(2): 170-76.

Benabou, Roland, and Jean Tirole. 2006. "Incentives and Prosocial Behavior." American Economic Review, 96(5): 1652-78.

Bernheim, B. Douglas. 1994. “A Theory of Conformity.” Journal of Political Economy, 102(5): 841-77.

Bodner, Ronit, and Drazen Prelec. 2002. "Self-Signaling in a Neo-Calvinist Model of Everyday Decision Making." In Psychology and Economics, Vol. II, ed. Isabelle Brocas and Juan D. Carillo. Oxford, UK: Oxford University Press.

Bohnet, Iris, and Dorothea Kübler. 2005. “Compensating the Cooperators: Is Sorting in the Prisoner's Dilemma Possible?" Journal of Economic Behavior and Organization, 56(1): 61-76.

Botelho, Anabela, Glenn W. Harrison, Lígia M. Costa Pinto, and Elisabet E. Rutström. 2005. "Social Norms and Social Choice." University of Central Florida Department of Economics Working Paper 2005-23.

Broberg, Tomas, Tore Ellingsen, and Magnus Johannesson. 2007. "Is Generosity Involuntary?" Economics Letters, 94(1): 32-37.

Camerer, Colin. 2003. Behavioral Game Theory: Experiments in Strategic Interaction. Princeton, NJ: Princeton University Press.

Camerer, Colin F., and Robin M. Hogarth. 1999. "The Effects of Financial Incentives in Experiments: A Review and Capital-Labor-Production Framework." Journal of Risk and Uncertainty, 19(1-3): 7-42.

Camerer, Colin, and Dan Lovallo. 1999. "Overconfidence and Excess Entry: An Experimental Approach.” American Economic Review, 89(1): 306-18.

Cameron, Lisa A. 1999. "Raising the Stakes in the Ultimatum Game: Experimental Evidence from Indonesia." Economic Inquiry, 37(1): 47-59.

Charness, Gary, and Martin Dufwenberg. 2006. "Promises and Partnership." Econometrica, 74(6): 1579-1601.

Dana, Jason, Daylian M. Cain, and Robyn M. Dawes. 2006. “What You Don’t Know Won’t Hurt Me: Costly (But Quiet) Exit in Dictator Games." Organizational Behavior and Human Decision Processes, 100(2): 193-201.

Dana, Jason, Roberto A. Weber, and Jason Xi Kuang. 2007. "Exploiting Moral Wiggle Room: Experiments Demonstrating an Illusory Preference for Fairness.” Economic Theory, 33(1): 67-80.

DellaVigna, Stefano, John A. List, and Ulrike Malmendier. Forthcoming. "Testing for Altruism and Social Pressure in Charitable Giving." Quarterly Journal of Economics.

Dillenberger, David, and Philipp Sadowski. Forthcoming. "Ashamed to Be Selfish." Theoretical Economics.

Dohmen, Thomas, and Armin Falk. 2006. "Performance Pay and Multi-Dimensional Sorting: Productivity, Preferences and Gender.” Institute for the Study of Labor (IZA) Discussion Paper 2001.

Duffy, John, and Tatiana Kornienko. 2010. "Does Competition Affect Giving? An Experimental Study." Journal of Economic Behavior and Organization, 74(1-2): 82-103.

Eriksson, Tor, and Marie-Claire Villeval. 2004. "Other-Regarding Preferences and Performance Pay-An Experiment on Incentives and Sorting." Institute for the Study of Labor (IZA) Discussion Paper 1191.

Erkal, Nisvan, Lata Gangadharan, and Nikos Nikiforakis. Forthcoming. "Relative Earnings and Giving in a Real-Effort Experiment." American Economic Review.

Fehr, Ernst, Urs Fischbacher, and Elena Tougareva. 2002. "Do High Stakes and Competition Undermine Fairness? Evidence from Russia." University of Zurich IEW Working Paper 120.

Fehr, Ernst, and Simon Gächter. 2000. "Fairness and Retaliation: The Economics of Reciprocity." Journal of Economic Perspectives, 14(3): 159-81.

Fehr, Ernst, and Klaus M. Schmidt. 1999. "A Theory of Fairness, Competition, and Cooperation." Quarterly Journal of Economics, 114(3): 817-68.

Fehr, Ernst, and Klaus M. Schmidt. 2002. "Theories of Fairness and Reciprocity: Evidence and Economic Applications." In Advances in Economics and Econometrics: Theory and Applications, Eighth World Congress, Vol. 1, ed. Mathias Dewatripont, Lars Peter Hansen, and Stephen J. Turnovsky, 208-57. Cambridge, UK: Cambridge University Press. 
Grossman, Zachary. 2009. "Self-Signaling versus Social-Signaling in Giving." UC Santa Barbara Department of Economics Working Paper 712009.

Gürerk, Özgür, Bernd Irlenbusch, and Bettina Rockenbach. 2006. "The Competitive Advantage of Sanctioning Institutions." Science, 312(5770): 108-11.

Haigner, Stefan, Martin Kocher, and Matthias Sutter. 2006. "Choosing the Stick or the Carrot? Endogenous Institutional Choice in Social Dilemma Situations." Center for Economic and Policy Research (CEPR) Discussion Paper 5497.

Hamman, John R., George Loewenstein, and Roberto A. Weber. 2010. "Self-Interest Through Delegation: An Additional Rationale for the Principal-Agent Relationship." American Economic Review, 100(4): 1826-46.

Harrison, Glenn W., Morten I. Lau, and Elisabet E. Rutström. 2009. "Risk Attitudes, Randomization to Treatment, and Self-Selection Into Experments." Journal of Economic Behavior and Organization, 70(3): 498-507.

Harrison, Glenn W., and John A. List. 2004. "Field Experiments." Journal of Economic Literature, 42(4): 1009-55.

Hoffman, Elizabeth, Kevin A. McCabe, and Vernon L. Smith. 1996. "On Expectations and the Monetary Stakes in Ultimatum Games.” International Journal of Game Theory, 25(3): 289-301.

Kandel, Eugene, and Edward P. Lazear. 1992. "Peer Pressure and Partnerships." Journal of Political Economy, 100(4): 801-17.

Lacetera, Nicola, Mario Macis, and Robert Slonim. Forthcoming. "Will There Be Blood? Incentives and Substitution Effects in Pro-social Behavior." American Economic Journal: Economic Policy.

Lazear, Edward, Ulrike Malmendier, and Roberto Weber. 2010. "Sorting, Prices, and Social Preferences." National Bureau of Economic Research Working Paper 12041.

Lazear, Edward, Ulrike Malmendier, and Roberto Weber. 2012. "Sorting in Experiments with Application to Social Preferences: Dataset." American Economic Journal: Applied Economics. http:// dx.doi.org/10.1257/app.4.1.136.

MacKinnon, James G., and Halbert White. 1985. "Some Heteroskedasticity-Consistent Covariance Matrix Estimators with Improved Finite Sample Properties." Journal of Econometrics, 29(3): 305-25.

Milgram, Stanley. 1963. "Behavioral Study of Obedience." Journal of Abnormal and Social Psychology, 67(4): 371-78.

Mullahy, John. 1986. "Specification and Testing of Some Modified Count Data Models." Journal of Econometrics, 33(3): 341-65.

Niederle, Muriel, and Lise Vesterlund. 2007. "Do Women Shy Away from Competition? Do Men Compete Too Much?" Quarterly Journal of Economics, 122(3): 1067-1101.

Palfrey, Thomas R., and Svetlana Pevnitskaya. 2008. "Endogenous Entry and Self-Selection in Private Value Auctions: An Experimental Study." Journal of Economic Behavior and Organization, 66(3-4): 731-47.

Rick, Scott, and Roberto A. Weber. 2010. "Meaningful Learning and Transfer of Learning in Games Played Repeatedly without Feedback." Games and Economic Behavior, 68(2): 716-30.

Slonim, Robert, and Ellen Garbarino. 2008. "Increases in Trust and Altruism from Partner Selection: Experimental Evidence." Experimental Economics, 11(2): 134-53.

Tadelis, Steven. 2008. "The Power of Shame and the Rationality of Trust." Unpublished. 